\title{
Chebyshev Polynomials in Collocation Methods for Solving Singular Perturbation Problems
}

\author{
Dr.Khalid. Mindeel. M. Al-Abrahemee \\ Department of Mathematics, College of Education / University of AL-Qadisiyha \\ (Email: $\underline{\text { Khalid.mohammed@qu.ed) }}$
}

Received:- 17/5/2016

Accepted:-22/1/2017

\begin{abstract}
This paper discourse the utility Momentmethod on second, third and fourth kind Chebyshev polynomials as attempt functions in solution singular perturbation problems with boundary condition. The process is computational very unmingled and magnetic. Applications are justly demonstrated through numerical examples to illustrated the effectiveness and easiness of the approximate, all the calculation outcome are obtain using Matlab.
\end{abstract}

Keywords: Singular perturbation problems; Chebyshev Polynomials ;Ordinary differential equation; Two point boundary value problem; Boundary layer.

Physical Classification QA299.6- 433 


\section{Introduction}

Singulare perturbation problems include a small perturbation parameter $\varepsilon$, rising very repeatedly in manybough of applied mathematics such as, fluide dynamiecs, quantume mechaniecs, chemicale reactor theory, elasticity, aerodynamicse, and the other dominion of the big mankind offluid motion. A few noticeable exemplify are Boundary stratum problems, the drift-diffusion equation of semiconductor invention modeling. These problems have allow a important amount of care in elapsed and recall years . It is well given actuality that the resolution of singular perturbation problems display a multi scaler charcter, that is, there are thin shift layer where the disruption modify fast, while hence from the layers the resolution carry ragularly and modify tardly. Therefore, the numerical dealing of singularly perturbed problems immediate some mayor compuetational difficulty. If we referthe existent canonical numerical method for solution these problems, huge oscillationse may proceed and taint the resolution in the whole period for of the boundary layer behavior. Thus, more effective and simplist computtional technique are request to resolve singulaerly perturbad twoboundary value problems. The examine paper by Kadalbajeoo and Reddy [1,2]. Natesan and Bawa [3], have study singularly perturbed reaction diffusion Robin boundary-value problems and say an almost second-order

(up to a logarithmic factor) uniformly converging plan, which is a proper alliance of the canonical limited distinction plan and the cubic spline scheme. The intend plan has been appropriate on a piece-wise uniform Shishkin mess. Andargie and Reddy[4] have immediate a numerical integration way for the disruption of general singularly perturbed two-point boundary value problems with mixed conditions of left or right end boundary layer. In this way the primary secondorder differential equation has been refund by an approaching first order differentail eqaution with a small digress evidence and then worn the trapezoid formula, a three expression return relationship has been holdand solution by Thomas algorithmic program. For a elaborate disputation on singalur perturbatione problems one may relate to the books and hie level monographse : O'Maley [5], Nayfeeh [6], Keovorkian and Cole [7], Bendar and Orszeag [8], Farrel et. al. [9], and Roose et. al. [10]. The numerical management ofsingularly perturbed problems instant some adult computational difficulties and in late years a huge number of peculiar discourse methods have been intend to supply correct numereical solution [11-15] by Kadalebajoo. This typify of problem has been intensiveely learned analyticaly and itis understood that its resolution commonly has a multi scale character; i.e. It faetures regieons called "boundary layers" where the breachmodify fast. And these equations as well as numericale methodes have been learned by a number of author [16-20]. In this paper, produce modern Method to Approximate Solution of the singularly perturbed problems with boundary condition on Chebyshev polynomial .

\section{Definitions of chebyshev polynomials}

In this part, we give an preliminary to the Chebyshev polynomials and their fundamental properties. See the regard [21- 24] for more details.

\subsection{The first-kind Chebyshev polynomial $\tau_{n}$ [25]}

The first kindof Chebyshev polynomial $\operatorname{Tn}(x)$ of degree $n$, give details by:

$\mathrm{T}_{\mathrm{n}}=\operatorname{cosn} \theta$ when $\times=\cos \theta \quad \ldots . .(1)$.

If the array of the varieable $x$ is the period $[-1,1]$, then the range of the confortmable ariable $\theta$ can be in use as $[0, \pi]$. These range are transversal in contrary directiones, since $x=-1$ agree to $\theta=\pi$ and $x=1$ agree to $\theta=0$.

It is well implicit the $\cos n \theta$ is a polynamial of degre $n$ in $\cos \theta$, and inded we are easy with the introductory formula

$\cos 0 \theta=1, \cos 1 \theta=\cos \theta, \operatorname{Cos} 2 \theta=$ $2 \cos 2 \theta-1, \cos 3 \theta=4 \cos 3 \theta-$ 
$3 \operatorname{Cos} \theta, \operatorname{Cos} 4 \theta=8 \operatorname{Cos} 4 \theta-8 \operatorname{Cos} 2 \theta+$ $1, \ldots$

The first kind of Chebyshev polynomials $\mathrm{T}_{\mathrm{n}}(\mathrm{X})$ definitely explain by the vocation return detail. Set

$$
\begin{gathered}
\tau_{0}(\times)=1 \text { and } \tau_{1}(\times)=\times \text {, then } \tau_{n}(\times)=2 \times \\
\tau_{n-1}(\times)-\tau_{n-2}(\times) \quad n=1,2, \ldots \quad(2) .
\end{gathered}
$$

The properties of Chebyshev polynomialscan be formulate as:-[ 25] 1-They are rectangular with moment duty $w(x)=\frac{1}{\sqrt{1-x^{2}}}$ on the period $[-1,1]$ that is:-

$$
\int_{-1}^{1} \frac{1}{\sqrt{1-x^{2}}} \tau_{n}(x) \tau_{m}(x) d x=\left\{\begin{array}{c}
0 n=m \\
\pi n \neq m \\
\frac{\pi}{2} n=m=1,2, .
\end{array}\right.
$$

And

$$
\begin{gathered}
\tau_{0} x=1, \tau_{1} x=x, \tau_{m+1} x \\
=2 x \tau_{m}(x)-\tau_{m-1}(x) \quad \ldots . .(3) .
\end{gathered}
$$

\subsection{The second- kind Chebyshev Polynomials}

\section{Un [25]}

The second kind of Chebyshev polynomial $\mho \mathrm{n}(\mathrm{x})$ of degre $\mathrm{n}$ in $\mathrm{x}$ definite by

$\mathrm{Un}(\times)=\sin (n+1) \theta / \sin \theta$ when $x=$ $\cos \theta \ldots$ (4)

The runges of $\times$ and $\theta$ are the same as for $\tau_{\mathrm{n}}(\times)$. The basic formula give

$\sin 1 \theta=\sin \theta, \sin 2 \theta=2 \sin \theta \cos \theta, \sin \theta 3 \theta$ $=\sin \theta(4 \cos 2 \theta-1), \sin 4 \theta=\sin \theta(8 \cos 3 \theta-$ $4 \cos 4 \theta), \ldots$.

, so the functions (4) is in fact a polynomial in $\cos \theta$, and we may at once take that

$\mho_{0}(x)=1, \mho_{1}(x)=2 x, \mho_{2}(\times)=4 \times 2-$ $1, \mho_{3}(\times)=8 \times 3-4 \times$.

By confederate the trigonometric sameness $\sin (n+1) \theta+\sin (n-1) \theta=2 \cos \theta \sin n \theta$
We get that $\operatorname{Un}(\times)$ satiate the return detail

$$
\begin{aligned}
\mho_{n}(\times)=2 x \mho_{n}-1(\times)-\mho_{n}-2(\times), n \\
=2,3, \ldots \text { with } U_{0}(\times) \\
=1, \mho_{1}(\times)=2 \times \ldots \ldots .
\end{aligned}
$$

\subsection{The Third and Fourth kind Chebyshev Polynomials $V_{n}$ and $W_{n}$ :-[25]}

Therese other familiesof polynomails $V_{n}(x)$ and $\mathbf{w}_{\mathrm{n}}(x)$ may be create, which are told to $\tau_{n}(x)$ and $\mho_{n}(x)$ butwhich have trigonomtric definition twist the half angle $\theta / 2$ (where $x=$ $\cos \theta$ as before. The Chebyshev polynomails $V_{n}(x)$ and $F_{n}(x)$ of the third and fourth kinds are polynomails of degree $n$ in $\times$ :-

$$
\begin{aligned}
& \mathbf{V}_{n}(\times)=2 x \mathbf{V}_{n-1}(\times)-\mathcal{H}_{n-2}(x) \text { with } \mathbf{V}_{0}(\times) \\
& =1, \mathbf{V}_{1}(\times)=2 \times-1 . \ldots \ldots \ldots(6) \\
& \begin{aligned}
\mathbf{W}(\times)=2 \times \mathbf{W}_{n-1}(x)-\mathbf{W}_{n-2}(\times) \text { with } W_{0}(x) \\
=1, \mathbf{W}_{1}(\times) \\
=2 \times+1 \ldots \ldots(7) \quad \text { where } n \\
=2,3,4, . . .
\end{aligned}
\end{aligned}
$$

then

$$
\begin{aligned}
& \mathbf{V}_{0}(\times)=1, \mathbf{V}_{1}(\times)=2 \times-1, \mathbf{V}_{2} \times \\
& =4 x^{2}-2 \times-1, V_{3}(\times) \\
& =8 x^{3}-4 x^{2}-4 \times+1 \ldots . \\
& \text { and } \\
& \begin{aligned}
\mathbf{V}_{0}(\times)=1, \mathbf{V}_{1}(\times)= & 2 \times+1, \mathbf{V}_{2} \times \\
= & 4 x^{2}+2 \times-1, V_{3}(\times) \\
= & 8 x^{3}+4 x^{2}-4 \times-1 \ldots
\end{aligned}
\end{aligned}
$$

Thus $\mathbf{V}_{\mathrm{n}}(\times)$ and $\mathbf{W}_{\mathrm{n}}(\times)$ plowshare exactly the plowshare accurately the $\tau_{n}(x), \mho n(x)$ and their production contend only in the rescriptions of the initial condition $n=1$.

\section{Descript method}

The method(Moment) is one of theefficacy remaining methods, There is a previous study to discuss type the first kind and the second kind by scientists respectively by Sarker and $\mathrm{Su}$ usefulness in [26] and Abdolerza, Farhad and Jafar amended in [27]. And to illustrate the new method of research we think the following 
sacond order linear singalur perturebation probleme with two-point boundary conditions:-

$\left.M[y(\times)]=\varepsilon y^{\prime \prime}+p(\times) y^{\prime}+q(\times) y=f(\times) 10\right)$

with b.cy $(a)=g_{0}, y(b)=g_{1}$

where $x \in[a, b]$ andthep, $q$ and $f$ are continuos function on $[\mathrm{a}, \mathrm{b}]$ and $0<\varepsilon \ll 1$. The problm of findeng an approch resolution to the singular perturbation problem (10) is often possess by pretentious the solution $\mathrm{y}(\mathrm{x})$ as :-

$\mathrm{y}_{\mathrm{N}}(\mathrm{x})=\sum_{\mathrm{i}=0}^{\mathrm{N}} \mathrm{d}_{\mathrm{i}} \mathrm{C}_{\mathrm{i}}=\frac{1}{2} \mathrm{~d}_{0} \mathrm{C}_{0}(\mathrm{x})+\mathrm{d}_{1} \mathrm{C}_{1}(\mathrm{x})+$

$\cdots+\mathrm{d}_{\mathrm{N}} \mathrm{C}_{\mathrm{N}}(\mathrm{x})$

for all $x \in[a, b][25]$.

Where $\mathrm{Ci}$ 's are kind Chebyshv polynomail defined in (5), (8) and (9). ( second, third and fourth) This approach must satiate the baundary

conditiones (11), exchang (12) in (10) we get the relics in the differential equation:-

$\mathrm{E}(\times)=|M(y)(\times)-f(\times)|$

\section{The Solution of Second Order SPBVP Using Moment Method}

If we have a second order of singular perturbation problem with boundary conditions (SPBVP)

$\varepsilon y^{\prime \prime}+p(\times) y^{\prime}+q(\times) y=f(\times) \quad(14)$
with $\quad$ bc $\quad y(a)=g_{0}, y(b)=g_{1}$
and $\quad 0<\varepsilon \ll 1$

Can be approximated the unknown function $\mathrm{u}(\mathrm{x})$

by:- $\mathrm{y}_{\mathrm{N}}(\mathrm{X})=\sum_{\mathrm{i}=0}^{\mathrm{N}} \mathrm{d}_{\mathrm{i}} \mathrm{C}_{\mathrm{i}}(\mathrm{X})$

where $\mathrm{Ci}$ 's are the second, third and fourth kind Chebyshev polynomiales. since these approximation mustsatisfy the b .c , we get:-

$$
\begin{gathered}
\begin{array}{r}
\begin{array}{r}
y(a)= \\
2
\end{array} d_{0} C_{0}(a)+d_{1} C_{1}(a)+\cdots+d_{N} C_{N}(a) \\
=g_{0}
\end{array} \\
\text { hence } \quad \mathrm{d}_{0}=2\left(\frac{\mathrm{g}_{0}-\sum_{\mathrm{i}=1}^{\mathrm{N}} \mathrm{d}_{\mathrm{i}} \mathrm{C}_{\mathrm{i}}(\mathrm{a})}{\mathrm{C}_{0}(\mathrm{a})}\right)
\end{gathered}
$$

$y(b)=\frac{1}{2} d_{0} C_{0}(b)+d_{1} C_{1}(b)+\cdots+d_{N} C_{N}(b)=g_{1}$

hence

$\mathrm{d}_{1}=\frac{1}{\mathrm{C}_{1}(\mathrm{~b})}\left[\left(\left(\mathrm{g}_{1}-2\left(\frac{\mathrm{g}_{0}-\sum_{\mathrm{i}=1}^{\mathrm{N}} \mathrm{d}_{\mathrm{i}} \mathrm{C}_{\mathrm{i}}(\mathrm{a})}{\mathrm{C}_{0}(\mathrm{a})}\right)\right) \frac{\mathrm{C}_{0}(\mathrm{~b})}{2}\right)-\right.$

$\left.\sum_{\mathrm{i}=2}^{\mathrm{N}} \mathrm{d}_{\mathrm{i}} \mathrm{C}_{\mathrm{i}}(\mathrm{b})\right]$

By substitute equation (16) and (17) into (15) we get

$$
\begin{aligned}
& \mathrm{y}_{N}(x)=2\left(\frac{g_{0}-\sum_{i=1}^{N} d_{i} C_{i}(a)}{C_{0}(a)}\right) C_{0}(x)+ \\
& \frac{1}{C_{1}(b)}\left[\left(\left(g_{1}-2\left(\frac{g_{0}-\sum_{i=1}^{N} d_{i} C_{i}(a)}{C_{0}(a)}\right)\right) \frac{C_{0}(b)}{2}\right)-\right. \\
& \left.\sum_{i=2}^{N} d_{i} C_{i}(b)\right] C_{1}(b)+\sum_{i=2}^{N} d_{i} C_{i}(x),
\end{aligned}
$$

Now we use oparator form to get:- $M[y]=f(x)$ and we defined $M$ is $M[y(x)]=\varepsilon \frac{d^{2}}{d x^{2}} y_{N}+$ $p(x) \frac{d}{d x} y_{N}+q(x) y_{N} \quad$ We can conclude $E(x)=M[y]-f(x)$ such that $t w_{0}, w_{1}, \ldots, w_{N}$ linearly independen on period $[a, b]$ that is:-

$\int_{a}^{b} W_{j}(\times) E(\times) d x=0 j=1,2, \ldots \ldots, N$ where $w_{j}=x^{j}$

Now we solve the system of $\mathrm{N}-1$ equations by Gaussian elimination process to find exchange in eq.(14) to hold the approaching solutionof $\mathrm{z}(\mathrm{x})$.

\section{Numerical Examples}

Consider the following linear two-point singular perturbation problem:-

Example 5.1[28]

Consider the following linear two-point singular perturbation problem:-

$\varepsilon y^{\prime \prime}(\times)-\times y^{\prime}(\times)-y(\times)=f(\times)=$ $\left(\frac{x+1}{\varepsilon}-1\right) e^{\frac{x+1}{\varepsilon}}-2\left(\frac{x-1}{\varepsilon}+1\right) e^{\frac{x-1}{\epsilon}}$ ، boundary condition $\mathrm{y}(-1)=1, \mathrm{y}(1)=2$, and exact solution is $\mathrm{y}=\mathrm{e}^{-(x+1) / \varepsilon}+2 \mathrm{e}^{(x-1) / \varepsilon}, \varepsilon=$ $10^{-3}$. 
By use moment method for this problem with $\mathrm{N}=6$ we get the approximat solution

$$
\mathrm{y}_{\mathrm{N}}(\mathrm{x})=\sum_{\mathrm{i}=0}^{6} \mathrm{~d}_{\mathrm{i}} \mathrm{C}_{\mathrm{i}}(\times)
$$

To illustration of this example then the compare betwen the exactand approxemated solution and find the error by M.S.E from table (1). Figure (1) shows a illustration betweenthe analytic solution and the approximat solution of theproblem which is immediate in example (5.1) using The proposed methodof Chebeyshev polynomails in all its kinds .

\section{Example 5.2 [29]}

Suppose we have the following equation of linear two-point singular perturbation problem:-

$\varepsilon y^{\prime \prime}(\times)+y^{\prime}(\times)=f(\times)=0, y(0)=0,(1)=1$

And analytic solution is $\boldsymbol{y}(\boldsymbol{x})=\frac{1-e^{-\times / \varepsilon}}{1-e^{-1 / \varepsilon}}$, $\varepsilon=10^{-6}$

By use moment method for this problem with $\mathrm{N}=7$ we get the approximat solution

$$
\mathrm{y}_{\mathrm{N}}(\mathrm{x})=\sum_{\mathrm{i}=0}^{7} \mathrm{~d}_{\mathrm{i}} \mathrm{C}_{\mathrm{i}}(\mathrm{x})
$$

To illustration of this example then the compare betwen the exactand approxemated solution and find the error by M.S.E from table (2). Figure (2) shows a illustration betweenthe analytic solution and the approximat solution of theproblem which is immediate in example (5.2) using The proposed methodof Chebeyshev polynomails in all its kinds .

\section{Conclusions}

In this study, we used a new method to solve the problems of linear and nonlinear singular perturbation problems, which is one of the most important issues in life applications. The softness used was superior in accuracy and results through some examples used linear and nonlinear by numerical comparison between the analytical solution and the approximate solutions of Ghabayshiv Error through least square error.

\section{Reference}

[ 1] Kadalbajoo, M. K. and Reddy, Y. N. 1989. Asymptotic and Numerical Analysis of Singular
Perturbation Problems: A Survey, Applied Mathematics and Computation 30: 223-259.

[2] Prandtl, L. 1905. in Uber lussigkeitbewegung bei Kleiner Reibung, Verh. III., Int. Math. Kongresses, Tuebner, Leipzig, 484-491.

[3] Natesan, S. and Bawa, R. K. 2007. Secondorder Numerical Scheme for Singularly Perturbed Reaction-Diffusion Robin Problems, Journal of Numerical Analysis, Industrial and Applied Mathematics. 2, 3-4: 177-192.

[4] Andargie, A. and Reddy, Y. N. 2008. Numerical Integration Method for Singular Perturbation Problems with Mixed Boundary Conditions. Journal of Applied Mathematics and Informatics, 26, 5-6: 1273-1287.

[5] O'Malley, R. E. 1974. "Introduction to Singular Perturbations", Academic Press, New York.

[6] Nayfeh, A. H. 1973. "Perturbation Methods" , Wiley, New York.

[7] Kevorkian, J. and Cole, J. D. 1981. "Perturbation Methods in Applied Mathematics" , Springer, New York.

[8] Bender, C. M. and Orszag, S. A. 1978. "Advanced Mathematical Methods for Scientists and Engineers", McGraw-Hill, New York.

[9] Farrell, P. A., Hegarty, A. F., Miller, J. J., H., O'Riordan, E., and Shishkin, G. I. 2000. "Robust Computational techniques for Boundary Layers", Chapman and Hall/CRC Press.

[10] Roos, H. G., Stynes, M. and Tobiska, L. 1996. "Numerical Methods for Singularly Perturbed Differential Equations", Springer, Berlin.

[11] M. K. Kadalbajoo and D. Kumar, "Fitted Mesh B-Spline Collocation Method for Singularly Perturbed Differential-Difference Equation with Small Delay," Applied Mathematics and Computation, Vol. 204, No. 1, 2008, pp. 90-98.

[12] M. K. Kadalbajoo and K. K. Sharma, “A Numerical Method Based on Finite Difference for Boundary Value Problems for Singularly Perturbed Delay Differential Equations," Applied Mathematics and Computation, Vol. 197,No. 2, 2008, pp. 692-707. [13] M. K. Kadalbajoo and V. P. Ramesh, "Numerical Methods on Shishkin Mesh for Singularly Perturbed Delay Differential Equations with a Grid Adaptation Strategy," Applied Mathematics and 
Computation, Vol. 188, No. 2, 2007,pp.1816-1831.

[14] M. K. Kadalbajoo and V. P. Ramesh, "Hybrid Method for Numerical Solution of Singularly Perturbed Delay Differential Equationsy," Applied Mathematics and Computation, Vol. 187, No. 2, 2007, pp. 797814.

[15] M. K. Kadalbajoo and K. K. Sharma, "Numerical Analysis of Singularly Perturbed Delay Differential Equations with Layer Behavior," Applied Mathematic putation, Vol. 157, No. 1, 2004, s and Compp. 11-28.

[16] K. C. Patidar and K. K. Sharma, " $\varepsilon$ Uniformly ConverVol. 175, No. 1, 2006, pp. 864-890.

[17] M. H. Adhikari, E. A. Coutsias and J. K. Modic Solutions of a Singularly $\mathrm{P}$ clver, "Perierturbed Delay Differential Equation," Physica D, Vol. 237, No. 24, 2008, pp.3307-3321.

[18] I. G. Amirsliyeva, F. Erdogan and G. M. Amiraliyev, "A Uniform Numerical Method for Dealing with a Singularly Perturbed Delay Initial Value Problem," Applied Mathematics Letters, Vol. 23, No. 10, 2010, pp. 1221-1225.

[19] S. N. Chow and J. M. Paret, "Singularly Perturbed DelayDifferential Equations, Cuopled Nonlinear Oscillators,"North-Holland Publishing Company, Amsterdam, 1983.

[20] R. E. O'Malley Jr., "Introduction to Singular Perturbation,"Academic Press, New York, 1979.
[21] L. Fox and I. B. Parker, Chebyshev Polynomials in Numerical Analysis, Oxford University Press (C) 1968.

[22] William Karush, The Cres cent Dictionary of Mathematics, 7th Edition, MacMillan Publishing Co., Inc., 1974.

[23] Theo dore J. Rivlin, Chebyshev Polynomials: From Approximation Theory to Algebra and Numb er Theory, Wiley and Sons Copyright (C) 1990 by Wiley-Interscience. [24] Timothy Sauer, Numerical Analysis, Pearson Education Inc. (C) 2006 2012.

[25].J.C.Mason,D.C.Handcomb," hebyshev Polynomials", Boca Raton London Newyork Washington, D. C. 2003 by CRC Press LLC. [26]. T.K.Sarkar, C.Su "A Multicale Moment Method for Solving Fredholm integral Equation of the First Kind",Progress in Electromagnetics Research, PIER 17, 237-264,1997.

[27]. Abdolreza.G, Farhad.S \&Jafar.A "An improved Second Moment Method For Solution of Pure Advection Problems", International Journal for Numerical Methods in Fluids 2000; 959-977.

[28] Ta O Tang And Manfred R. Trummer, Bound Ary Layer Resolving Pseudo spectral Methods F Or Singular Perturbation Problems, 2006.

[29] Carl M. Bender, A radically new method for solving boundary-layer problems, 1996. 


\section{AL-Qadisiyah Journal of pure Science Vol.23 No. 2 Year 2018}

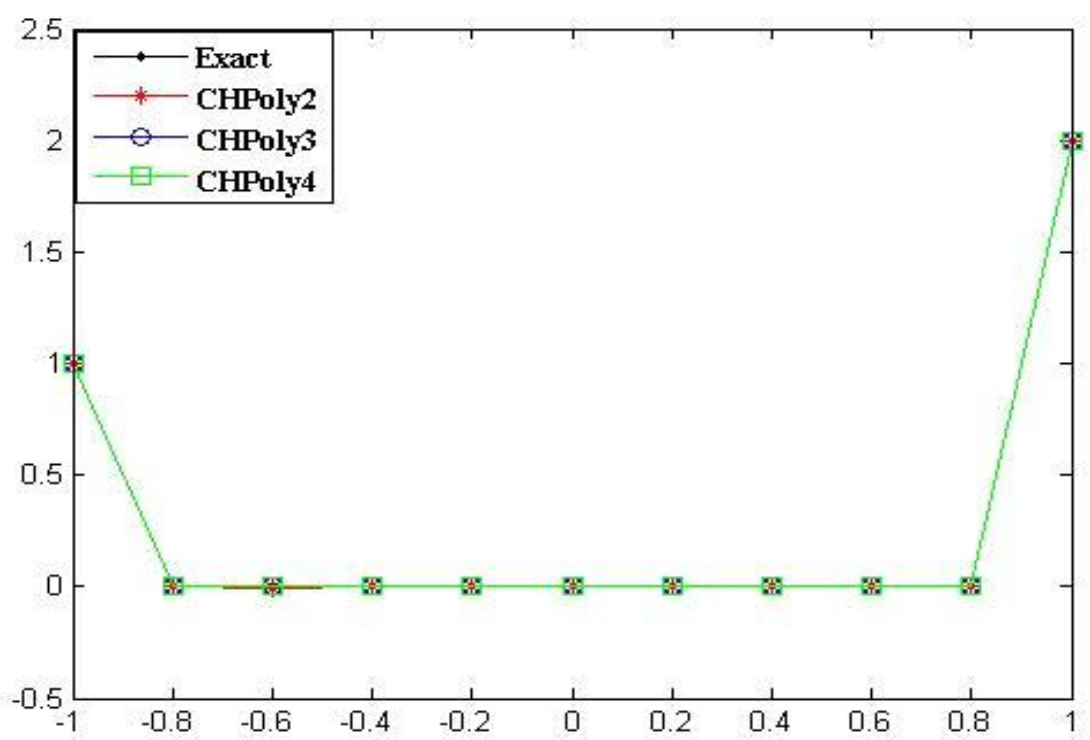

Figure(1) : shows a comparison between the exact solution and the approximate solution of the problem which is presented in example 5.1 .

Table(1): presents a comparison between the exact and approximated solution which depends on the least square error for example 5.1 .

\begin{tabular}{|c|c|c|c|c|}
\hline \multirow[b]{2}{*}{$x$} & Analytic solution & \multicolumn{3}{|c|}{ Suggested solutions } \\
\hline & $y a(x)$ & $\begin{array}{l}\text { second } \\
\text { - kind Chebyshev polyn }\end{array}$ & $\begin{array}{l}\text { third } \\
\text { - kind Chebyshev p }\end{array}$ & $\begin{array}{l}\text { fourth } \\
\text { - kind Chebyshev pol }\end{array}$ \\
\hline-1.0 & 1.0000000000 & 1.0000003937 & 1.0000000034 & 1.0000000000 \\
\hline-0.8 & 0.0000000000 & 0.0000000298 & 0.0073764358 & 0.0000000000 \\
\hline-0.6 & 0.0000000000 & -0.0027170337 & 0.0000001497 & 0.0011930953 \\
\hline-0.4 & 0.0000000000 & -0.0002514149 & -0.0000010480 & 0.0000000000 \\
\hline-0.2 & 0.0000000000 & -0.0000059206 & 0.0000033015 & -0.0001719885 \\
\hline 0 & 0.0000000000 & 0.0000168176 & 0.0000017426 & -0.0000959423 \\
\hline 0.2 & 0.0000000000 & 0.0000225346 & -0.0000007325 & 0.0000000000 \\
\hline 0.4 & 0.0000000000 & 0.0000246020 & -0.0000008292 & 0.0000000000 \\
\hline 0.6 & 0.0000000000 & -0.0000195530 & -0.0000012017 & -0.0013701290 \\
\hline 0.8 & 0.0000000000 & 0.0000008998 & 0.0000002269 & 0.0000000000 \\
\hline 1.0 & 2.0000000000 & 2.0000000063 & 2.0000000639 & 2.0000000000 \\
\hline & M.S.E & 0.0000006770 & 0.0000049465 & 0.0000003036 \\
\hline
\end{tabular}




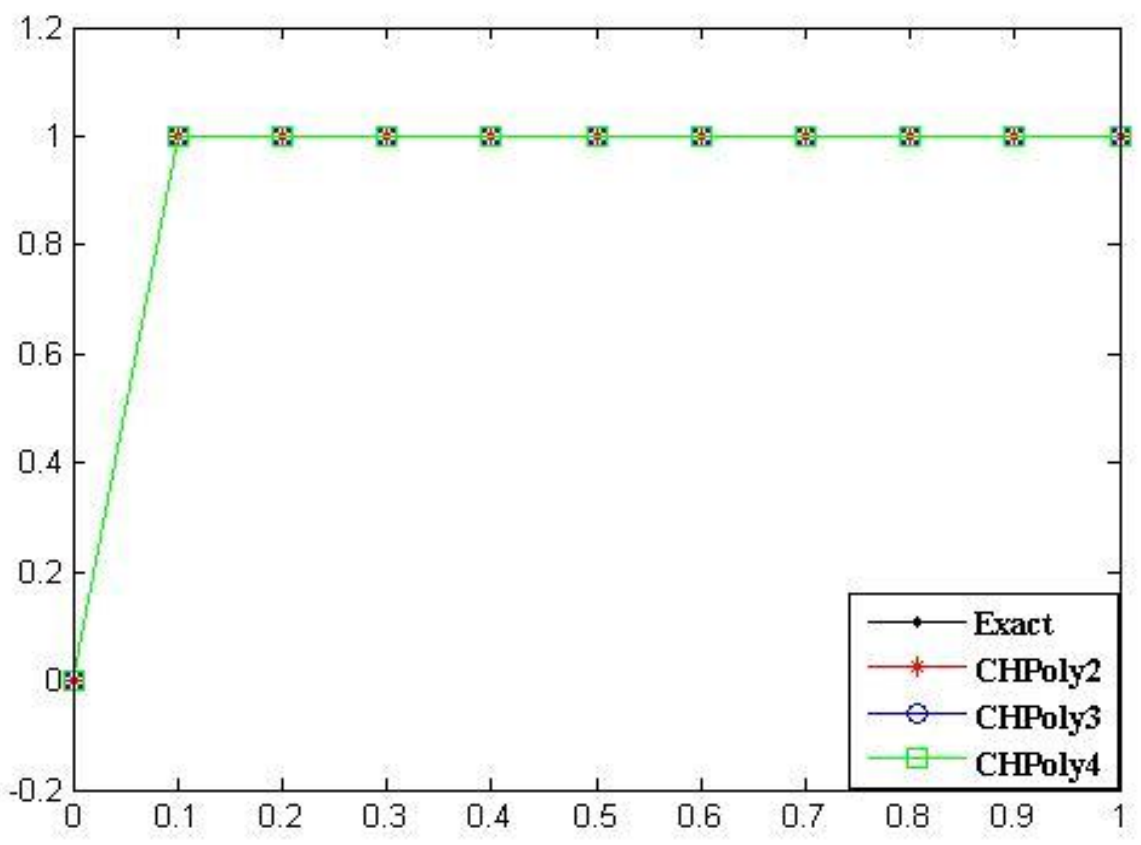

Figure (2): shows a comparison between the exact solution and the approximate solution of the problem which is presented in example (5.2) .

Table (2): presents a comparison between the exact and approximated solution which depends on the least square error for example 5.2 .

\begin{tabular}{|c|c|c|c|c|}
\hline \multirow{2}{*}{$\boldsymbol{x}$} & Analytic solution & \multicolumn{3}{|c|}{ Suggested solutions } \\
\cline { 2 - 5 } & $\mathbf{y a}(\mathbf{x})$ & $\begin{array}{l}\text { second } \\
\text { - kind Chebyshev poly }\end{array}$ & $\begin{array}{c}\text { third } \\
\text { - kind Chebyshev polyno }\end{array}$ & $\begin{array}{c}\text { fourth } \\
- \text { kind Chebyshev poly }\end{array}$ \\
\hline $\mathbf{0 . 0}$ & 0 & 0.0000130832 & 0.0000000001 & -0.0000000306 \\
\hline $\mathbf{0 . 1}$ & 1 & 1.0000034922 & 0.9999999996 & 0.9999999958 \\
\hline $\mathbf{0 . 2}$ & 1 & 1.0000554567 & 0.9999999998 & 1.0000000493 \\
\hline $\mathbf{0 . 3}$ & 1 & 0.9998675023 & 0.9999999997 & 0.9999998127 \\
\hline $\mathbf{0 . 4}$ & 1 & 1.0002554458 & 1.0002729360 & 1.0000210329 \\
\hline $\mathbf{0 . 5}$ & 1 & 0.9997890236 & 1.0000361803 & 1.0000016391 \\
\hline $\mathbf{0 . 6}$ & 1 & 1.0000808177 & 1.0000000116 & 0.9999966236 \\
\hline $\mathbf{0 . 7}$ & 1 & 1.0006286158 & 0.9999992516 & 1.0000018832 \\
\hline $\mathbf{0 . 8}$ & 1 & 1.0005880716 & 0.9999998711 & 1.0000086743 \\
\hline $\mathbf{0 . 9}$ & 1 & 0.9995769010 & 1.0000001175 & 1.0000136983 \\
\hline $\mathbf{1 . 0}$ & 1 & 0.9976329902 & 1.0000002701 & 1.0000167176 \\
\hline & L.S.E & 0.0000006054 & 0.0000000069 & 0.0000000001 \\
\hline
\end{tabular}


AL-Qadisiyah Journal of pure Science $\quad$ Vol.23 No.2 $\quad$ Year 2018

\title{
متعددة حدود جبيشيف لحل مسائل الاضطراب الشاذة
}

\author{
خالا منديل محمد

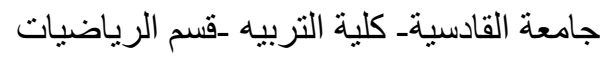 \\ Khalid_math98@yahoo.com: الاميل
}

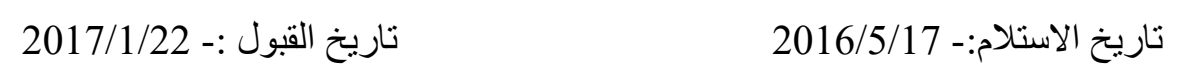

في هذا البحث استخدمت الطريقة اللحظية على متعدد حدود تشيبيثيف من من الرتبة الثانية والثالثة والرابعة

لحل مسائل الاضطراب المنفردة ذات الشروط الحدودية ـ الطريقة تكون سهلة حسابيا وفعالة وأظهرت التطبيقات على حد سواء من خلال أمثلة عددية لتوضيح كفاءة وبساطة الطريقة، ويتم الحصول على كل النتائج الحسابية باستخدام ماتلاب.

الكلمات المفتاحية:

مسائل اضطراب المفرد. متعددة حدود تشيبيشيف ، المعادلات التفاضلية العادية. مسائل القيم الحدودية ذات النقطتين. الطبقة الحدودية 